\title{
3rd International Summer Academy of Practical Dermatology 2013, Munich, 21 - 26 July, 2013
}

\begin{abstract}
BACKGROUND: For the third time, the International Summer Academy of Practical Dermatology is scheduled to take place in Munich, Germany. Following the success of the last ISA meeting which attracted over 900 participants from 70 different countries, ISA 2013 promises to provide participants with a unique global perspective of the latest developments in practical dermatology.

Originally based on the concept of the well-established German Meeting - the Munich Educational Week of Practical Dermatology - ISA 2013 now enjoys an international reputation of its own which is underpinned by the excellent faculty from around the world. This year's comprehensive scientific programme can be viewed in detail on the meeting website at www.isa2013.com.
\end{abstract}

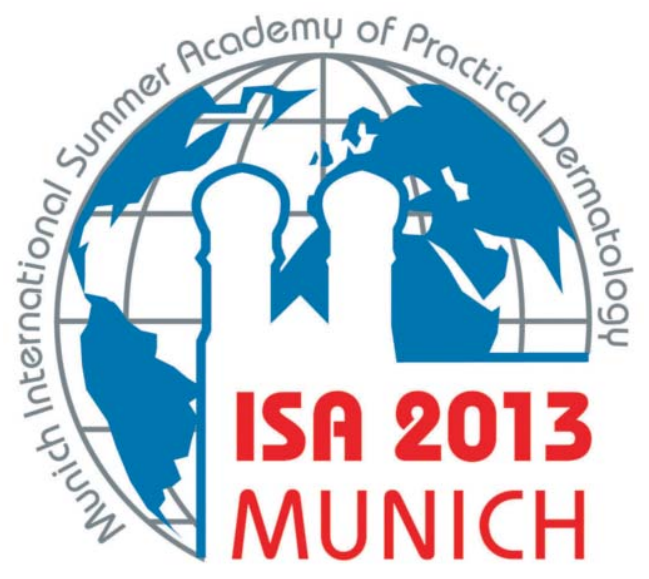

\section{PROGRAMME HIGHLIGHTS}

The morning sessions are devoted to keynote lectures and major plenary topics. The fact that the plenary sessions are dedicated to one lecture hall only ensures that participants are able to attend the entire plenary offer.

\section{Keynote Speakers include:}

Cyber Dermatology - Daniel Mark Siegel, Brooklyn/New York, USA

Aesthetic Dermatology - Jean Carruthers, Vancouver, Canada

Haemangiomas in Childhood - Ilona Frieden, San Francisco, USA

\section{Plenary Session Topics:}

Hair and Nails

Common Problems in Practical Dermatology I and II

Dermatology around the World I and II

Aesthetics and Lasers

Immune-mediated Skin Diseases

Clinical Spectrum of Eczema

Oncology

What's New in Infectious Diseases, Genetics, Dermatosurgery, Disease Entities in Dermatology,
Dermatotherapy

Each day, shortly after lunch, a one-hour symposium will review new developments in the field of dermatopharmacology and broaden the knowledge of important dermatological therapeutics.

\section{Important Focus on Practical Dermatology}

As indicated in the title of the congress, a special and intense focus is placed on the practical implementation of skills learned and presented during ISA 2013. The afternoons are entirely devoted to meetthe expert sessions, workshops and practical courses. Participants are provided with this unique opportunity to work closely with renowned experts in small groups and to practice skills in both lecture hall but also real-life clinic settings. The range of workshops is vast and is designed to serve both the interests of beginners as well as experienced dermatologists:

\author{
Meet the Expert Sessions: Dermatosurgery: \\ Virtual Reconstruction \\ Eczema in Dark Skin \\ Cutaneous Side Effects of New Drugs \\ Parasitic Diseases \\ Test your Diagnostic Skills - an Interactive Quiz
}


Pigmentary Disorders

Venous Disorders

Cutaneous Drug Eruptions

How do I use Biologicals

Leishmaniasis

Workshops: Leg Ulcers and Wound Healing

Entity and Stage-Adapted Treatment of

Cutaneous Lymphomas

BTX

Photodynamic Therapy

STD and HIV

Psoriasis and Related Disorders

Management of Scars

Paediatric Dermatology

Aesthetics

Practical Courses with Hands-On Training:

Patch Testing

Optical Coherence Tomography

Mycology

Laser Therapy

Dermatohistopathology for Beginners Basic

Dermatosurgery - Suturing and Knotting

Course on Pig Faces

Sonography

Trichology

Basic Dermoscopy and Pitfalls

Phlebology: Duplex-Sonography for Beginners

Important Note: Meet-the-Expert Sessions, Workshops and Practical Courses are limited in their participant size. Some courses require separate registration and an additional fee is payable. It is recommended that those interested in participating in these courses complete their registration as soon as possible.

\section{International Platform}

ISA 2013 also provides a unique opportunity for various national and international groups to meet and exchange their ideas in the field of practical dermatology. Several national societies will be holding special sessions to which all participants are invited to attend.

\section{ISA 2013 International Outreach Programme}

We are dedicated to providing opportunities to young dermatologists who do not necessarily have access to international meetings. Our Travel Grant and Educational Grant Programmes provide support to applicants from low income countries. Further information can be found at the ISA 2013 website.

\section{GENERAL INFORMATION}

Congress Name: 3rd Munich International Summer Academy of Practical Dermatology

Dates: 21 - 26 July, 2013

Venue: Holiday Inn Munich City Centre, Hochstrasse 3, 81669 Munich, GERMANY

Congress Website: www.isa2013.com

Scientific Organisers: Prof. Thomas Ruzicka

Dr. Tatjana Pavicic

Prof. Markus Braun-Falco

\section{Congress Organiser:}

INTERPLAN Fortbildungswoche $\mathrm{GmbH}$

Landsberger Str. 155

80687 Munich, GERMANY

Tel: +49-89-54 823473

Fax: +49-89-54823442

Email: isa@interplan.de 